\title{
THE PROLONGED AND DISTANT EFFECTS OF EXPERIMENTAL BRAIN INJURY ON CEREBRAL BLOOD VESSELS AS DEMONSTRATED BY RADIOACTIVE INDICATORS
}

\author{
BY \\ JAMES B. BRIERLEY \\ From the Department of Neuropathology, Institute of Psychiatry, Maudsley Hospital, London
}

The occurrence of oedema is a well-known clinicopathological consequence of damage to the brain and is commonly regarded as an accumulation of tissue fluid resulting from an increased permeability of cerebral blood vessels. Experimental evidence that such vascular changes may occur far beyond the limits of the lesion is scanty. Prados, Strowger, and Feindel (1945) exposed an area of the cerebral cortex of cats to air for several hours and then injected trypan blue intravenously. The brain was removed the next day and showed, in addition to dark staining of the exposed cortex, a diffuse blue coloration of both hemispheres. Bakay (1955) observed (in autoradiographs) increased penetration of radioactive phosphate into the whole of a hemisphere that had received an injection of 1 to $3 \mathrm{ml}$. of molten paraffin wax a day previously. By the second day this evidence of oedema was restricted to a zone $2 \mathrm{~mm}$. wide around the lesion.

Further evidence of remote effects was obtained by Tsang (1936) who ablated the rat visual cortex and demonstrated after varying survival periods that the lateral geniculate body on the same side was stained by intravenous carmine. This evidence of abnormal permeability was seen, in one instance, 153 days after the ablation.

Apart from these investigations, interest has centred largely on the local changes in permeability around lesions produced by such methods as coagulation of the intact dura (Caudill, Smith, French, Peyton, and Moore, 1951), coagulation of brain substance (Stern and Marshall, 1951; Broman, Radner, and Svanberg, 1949), stab wounds (Macklin and Macklin, 1920), and contusions (Syz, 1923; Stern and Marshall, 1951).

In the present investigation localized lesions of the rabbit cerebral cortex were produced by applying liquid oxygen to the intact skull, and the resulting changes in the cerebral vessels were detected after various periods of survival up to 14 weeks by injecting labelled di-iodo fluorescein (D.I.F.) and phosphate. The normal distribution of these substances in the rabbit nervous system has been reported previously (Brierley, 1953, $a$ and $b$ ).

\section{Methods}

A single litter of healthy adult rabbits was used fot each experiment. Three (or occasionally two) animals acted as controls. In the remainder lesions were made under nembutal anaesthesia by pouring liquid oxygern into a copper tube sealed on to the bare skull with vacuum grease (Fig. 1). The freezing time varied framo 10 to 25 seconds depending on the level of filling (roughly from one-third to four-fifths full). The severity of the lesion was graded later when the brain was remoye into " mild" (just visible), " moderate" (2-5 ninc diameter), and " severe" (6-8 mm. diameter). Recovery" of consciousness occurred in one to three hours excepte after some severe lesions when it was delayed up to:sikg hours with mild head retraction for up to a furthet

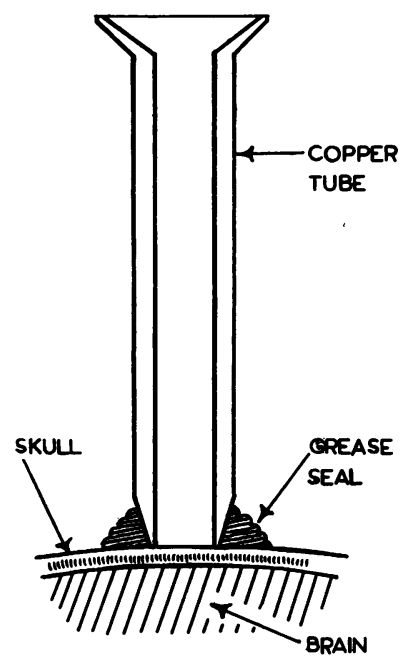

FIG. 1.-Vertical section of copper tube mounted on bare skut within grease seal. Length, $7 \mathrm{~cm}$; internal diameter, $1 \mathrm{~cm}$. 

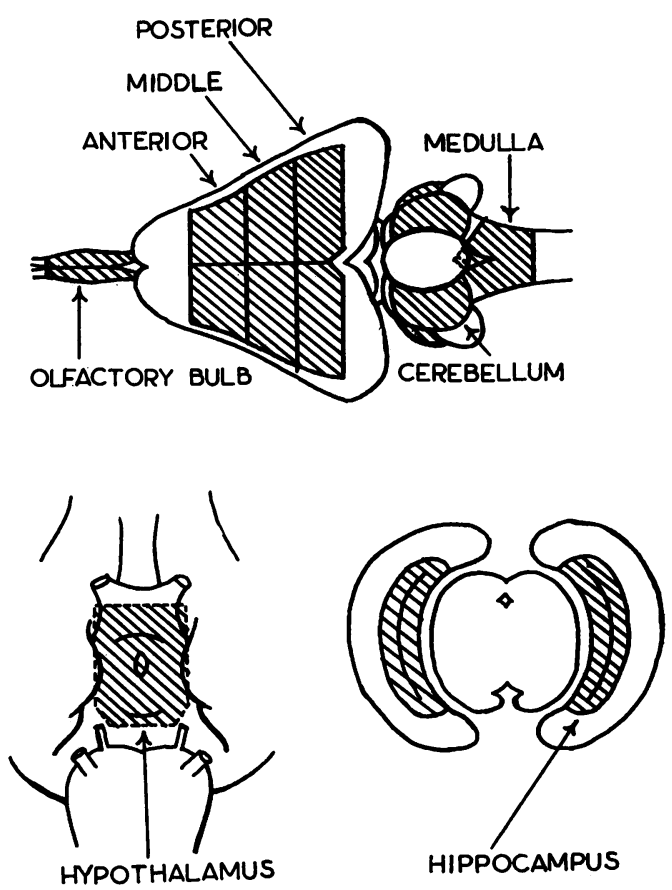

FIG. 2.-Diagrams of standard brain samples.

12 hours. No abnormalities in behaviour or motor function could be detected after a day and the skin incisions healed well. Freezing times of more than 25 seconds, however, were fatal.

After a period of survival which was different for each litter all the animals received a radioactive indicator intravenously. In the experiments with phosphate six litters were used and the animals (heparinized and under nembutal) received $10-250 \mu \mathrm{c}$. of ${ }^{32} \mathrm{P}$ in a small volume into an ear vein, and were allowed to survive for 10 minutes. Di-iodo fluorescein was given similarly to four litters in activities of ${ }^{131} \mathrm{I}$ from 170 to $850 \mu \mathrm{c}$. The survival period with D.I.F. was 15 minutes. The animals were killed by exsanguination. Samples of blood were taken (for radioassay of plasma or whole blood) on weighed dry filter paper discs (Reiss, Badrick, and Halkerston, 1949) which were then reweighed, dried in an oven at $100^{\circ} \mathrm{C}$, and radioassayed under an end window counter. The brain and spinal cord were rapidly removed, cleansed of obvious blood and blood vessels, and sampled according to the standard plan shown in Fig. 2, except in one litter in which the cortex was divided into anterior and posterior portions only. In the case of the cerebrum and cerebellum, the sample consisted of thin slices excluding, as far as possible, the white matter.

After homogenization, in trichloroacetic acid for ${ }^{32} \mathrm{P}$ and in alcoholic caustic soda for D.I.F., the samples were assayed in M.6 liquid counters and a figure for the relative uptake of tracer independent of the actual radioactive dose was obtained from the ratio:-

$$
\text { Tissue activity }=\frac{\text { Counts } / \mathrm{min} . / 100 \mathrm{mg} \text {. tissue }}{\text { Counts } / \mathrm{min} . / 100 \mathrm{mg} \text {. plasma }} \times 1000
$$

In the first three litters of the phosphate series the terminal plasma activity was not used, but instead the estimated whole blood activity at the time of injection (Brierley, 1953a). This procedure does not affect the interpretation of the results.

Histological Examination.-The brains of a series of animals that had received lesions of various intensities were removed at intervals up to seven months. After fixation in $10 \%$ formalin each brain was divided coronally through the centre of the lesion, one half being embedded in celloidin and the other used for the preparation of frozen sections. Celloidin sections were stained by the techniques of Nissl, Heidenhain, Mallory (phosphotungstic-acid-haematoxylin), and Van Gieson. Frozen sections were stained by the silver carbonate method for microglia, of Holzer for fibrous glia, and of Herxheimer for fat.

\section{Results}

The detailed experimental results are given in Tables I and II. At each site the scatter in the control samples within a litter was small. Various ways of expressing the difference between control and experimental tissue activities were considered. In the end it was decided arbitrarily to take notice of values that were $20 \%$ or more greater than the highest control.

Immediately after the injury, a high concentration of both phosphate and D.I.F. was to be found within the lesion and in the adjacent cortex.

For phosphate (Table I) the maximum cortical ratios occurred at 15 minutes $(31 \cdot 7)$ and decreased steadily thereafter but were still considerable (13.0) at 14 weeks. Contralateral cortical activity was increased from the outset, attained a maximum at 48 hours (12.6), and was only slightly increased at 14 weeks (1.5). Hypothalamic and medullary ratios were greatest at 90 minutes $(2 \cdot 8$ and $1 \cdot 5)$ and had returned to normal at 38 days.

For D.I.F. (Table II) the high activities in the lesion declined sharply from 30 minutes to seven days and at 41 days did not exceed $2 \cdot 3$. Contralateral cortical ratios, increased in all cases at seven days (maximum 11.6), were much reduced by 41 days (maximum 2.2). The brain-stem structures, hippocampus, and olfactory bulb showed maximum values at seven days and by 41 days only the hypothalamus and medulla had not returned to normal.

Throughout both series it was clear that the increases in tissue activity were greater with the more severe lesions. It is to be noted that the highest cortical values did not always occur within the lesion but might be found in either an adjacent ipsilateral segment or even in the contralateral cortex (Tables 
TABLE I

VALUES FOR PHOSPHATE ( ${ }^{32 P}$ )*

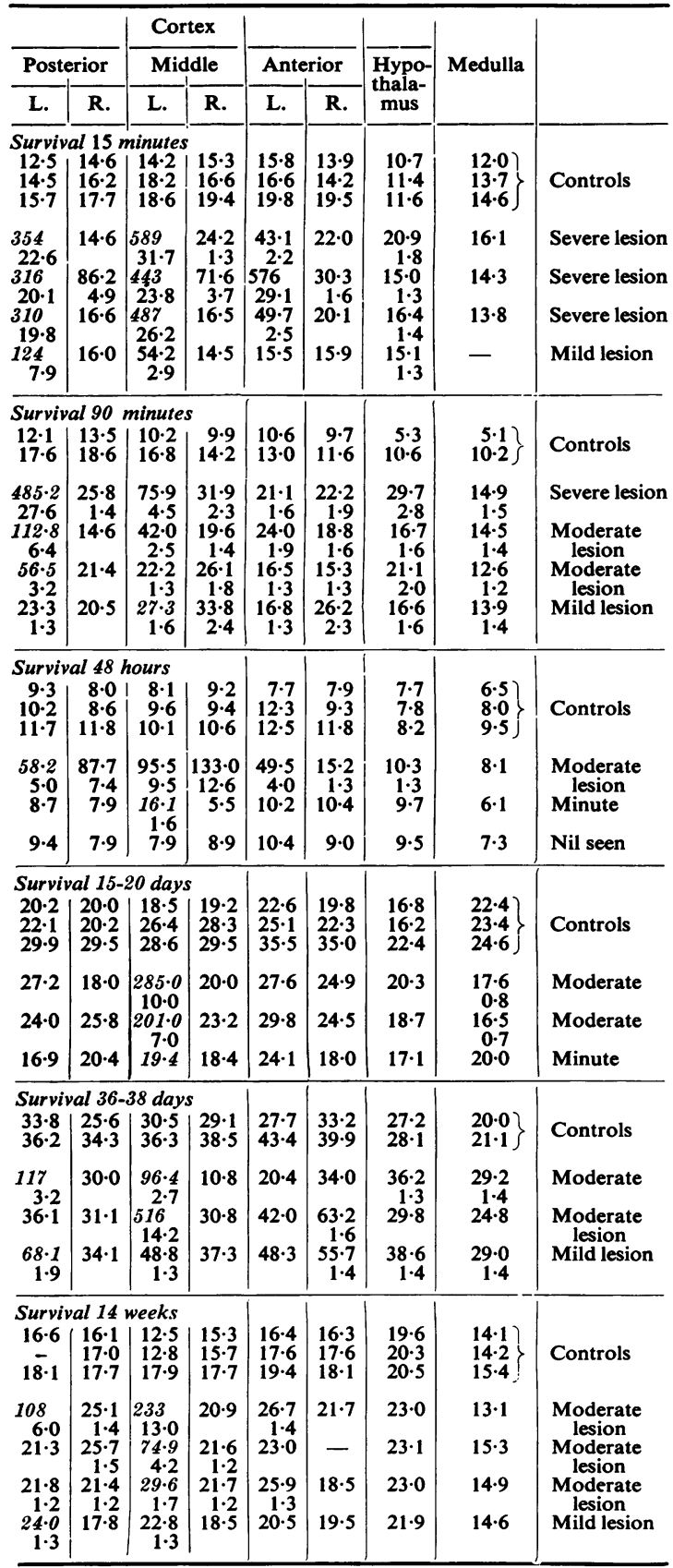

* In the tables all the values have printed below them the ratio of the experimental value to the highest control value (the smallest ratio found is therefore $1 \cdot 2$ ). When the sample included the lesion or part of it, the figure for tissue activity is printed in italics. The lesions were always placed in the left hemisphere. Each section presents the results from one litter.
I and II). These apparent anomalies may be ascribed in part to some loss of the frozen tissue due to its semifluid state (early) or its adherence to the meninges (late).

With the larger ratios it is apparent that the only way of accounting for the high concentrations of radioactivity in the specimens is to suppose that the tracer has passed out of the blood vessels as a resum of a real increase in permeability. For lower ratios, however, it is necessary to consider two othe possible factors, namely, transport of radioactivify in cerebrospinal fluid from the lesion to mose remote parts of the nervous system and an increass: in blood within the samples as a result of vasodilat俤 tion in vivo.

The role of the cerebrospinal fluid was eliminated by experiments on three rabbits with severe lesion $\vec{P}$ The survival periods were one, 19, and 24 hours before ${ }^{32} \mathrm{P}$ was given in the usual way. Cerebrospinfs fluid was collected by cisternal puncture after eight minutes, and the animals exsanguinated 10 minutes. At one and 24 hours there was ni detectable ${ }^{32} \mathbf{P}$ in the cerebrospinal fluid, but ${ }^{25}$ nine hours the activity referred to the terminal plasing activity in the usual way was 11 , i.e., less than normal cortex, but even this may have been due slight blood contamination which was noted. ff is therefore considered that ${ }^{32} \mathrm{P}$ in the cerebrosping fluid cannot account for even the smallest increas observed in the experimental samples.

Vasodilatation, however, proves to be of geieat importance, particularly in the interpretation ${ }^{+}$禺 results with D.I.F. It has been shown previousty (Brierley, 1953a) that in normal brain the vesse are virtually impermeable to D.I.F. and this substance had therefore been used to determine the amount of residual blood in the normal brain samples. Afteip an intravenous dose of D.I.F. at least four-fifths of the radioactivity of normal brain samples can removed by saline perfusion and the remaining onefifth is bound to some tissue elements. It follow that to increase the total sample activity in the ratio 1.2 (the critical level adopted here) woutel require a vasodilatation in vivo sufficient only increase the residual blood of the sample by $20 \%$ providing there was no change in permeabilit: Then also, perfusion would be expected to remole four-fifths of the increased total activity and to leave a proportionately increased amount of "fixed" dye.

The actual situation was clarified in a litter of fou animals, of which two acted as controls and tw\& received severe lesions. All received D.I.F. as usuăb but, before taking samples, one of the lesionef animals was perfused with a litre of saline. The 
TABLE II

VALUES FOR D.I.F.

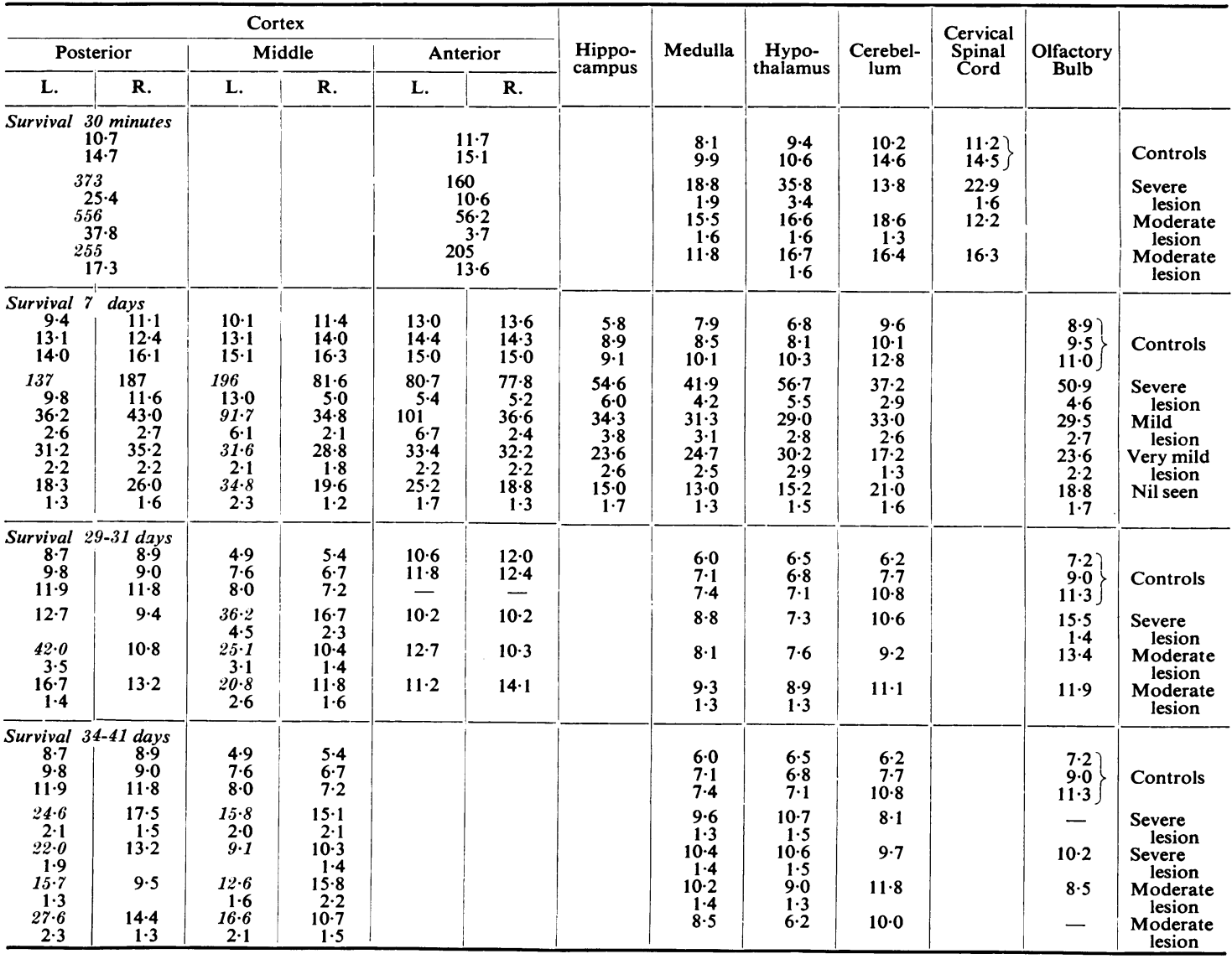

results are given in Table III. Comparing the two cortical samples it is seen that considerable permeability to D.I.F. must have developed as only $28 \%$ of the radioactivity was removed by perfusion. In the hypothalamus and medulla 73 and $72 \%$ of the activity is removed by perfusion but the remaining "fixed" fraction is in each case greater than the total activity of the unperfused control samples and

TABLE III

EFFECT OF PERFUSION ON EXPERIMENTAL ANIMALS

\begin{tabular}{|c|c|c|c|}
\hline & $\begin{array}{c}\text { Counts/min./ } \\
100 \mathrm{mg} .\end{array}$ & Exp./Control & Exp./Contro \\
\hline $\begin{array}{l}\text { Cortex (posterior) } \\
\text { Hypothalamus } \\
\text { Medulla }\end{array}$ & $\begin{array}{r}10 \cdot 8 \\
7 \cdot 9 \\
3 \cdot 9\end{array}$ & $\begin{array}{c}11.4^{*} \\
4.4 \\
3.9\end{array}$ & $\begin{array}{l}8 \cdot 1^{*} \\
1 \cdot 2 \\
1 \cdot 1\end{array}$ \\
\hline Animals & 2 controls & severe lesion & $\begin{array}{c}\text { severe lesion } \\
\text { perfused }\end{array}$ \\
\hline
\end{tabular}

* Activities as multiple of control values. from 5.5 to 6.0 times greater than their "fixed" fractions. Thus in the experimental animal the raised sample activities may be interpreted as the result of vasodilatation in vivo which produces an absolute increase in residual blood but also an absolute increase in dye bound to tissue. Whether the latter includes some dye that has passed through the vessel wall and thus represents a true increase in permeability cannot be decided from the present data.

In contrast to D.I.F., normal cerebral vessels are permeable to phosphate and the activity to be attributed to ${ }^{32} \mathrm{P}$ remaining in the blood vessels is relatively small. Brierley (1952) estimated this proportion as 20 to $27 \%$ using values for the residual blood of brain samples obtained with D.I.F. (Table IV). Direct perfusion experiments have confirmed this estimate (Table V). In a litter of six rabbits, two were ordinary controls, two were controls perfused before brain sampling, and two 
TABLE IV

AVERAGE TISSUE ${ }^{32} P$ ACTIVITIES (10 NORMALS) CORRECTED TO TERMINAL BLOOD ACTIVITY OF $1,000 \mathrm{C} / \mathrm{MIN}$./100 MG.

\begin{tabular}{|c|c|c|c|c|}
\hline & $\begin{array}{l}\text { Counts/ } \\
\text { min./ } \\
100 \mathrm{mg} .\end{array}$ & $\begin{array}{l}\text { Residual } \\
\text { Blood/ } \\
100 \mathrm{mg}\end{array}$ & $\begin{array}{c}\text { Residual } \\
\text { Blood as } \\
\text { Counts/ } \\
\text { min./ } \\
100 \mathrm{mg} .\end{array}$ & $\begin{array}{l}\text { Residual } \\
\text { Blood as } \\
\% \text { Total } \\
\text { Count }\end{array}$ \\
\hline $\begin{array}{l}\text { Cortex (posterior) } \\
\text { Hypothalamus } \\
\text { Medulla } \\
\text { Spinal cord }\end{array}$ & $\begin{array}{l}31 \cdot 0 \\
29 \cdot 7 \\
27 \cdot 3 \\
30 \cdot 4\end{array}$ & $\begin{array}{l}0.629 \\
0.722 \\
0.769 \\
0.845\end{array}$ & $\begin{array}{l}6 \cdot 29 \\
7 \cdot 22 \\
7 \cdot 69 \\
8 \cdot 45\end{array}$ & $\begin{array}{l}20 \cdot 3 \\
24 \cdot 3 \\
27 \cdot 0 \\
27 \cdot 8\end{array}$ \\
\hline
\end{tabular}

were given severe lesions 48 hours previously and one of these was perfused before sampling.

Table $\mathrm{V}$ shows that perfusion reduced the activity of the samples by between $10 \%$ and $30 \%$ in both the controls and the experimental animals. In the latter, the activities remaining in the samples are greater than those of the unperfused controls in all cases, the ratios being 2.4 for hypothalamus and 1.8 for medulla. Here again the increased total activities may be regarded as evidence of vasodilatation in vivo and the raised residual fractions as due to the associated increase in phosphate penetration.

TABLE V

PERFUSION OF CONTROL AND EXPERIMENTAL ANIMALS: ${ }^{32} P$

\begin{tabular}{|c|c|c|c|c|}
\hline & $\begin{array}{c}\text { Counts/ } \\
\text { min./ } \\
100 \mathrm{mg} .\end{array}$ & $\begin{array}{l}\text { Counts } \\
\text { Lost }\end{array}$ & $\begin{array}{l}\text { Experi- } \\
\text { mental/ } \\
\text { Control }\end{array}$ & $\begin{array}{l}\text { Experi- } \\
\text { mental/ } \\
\text { Control }\end{array}$ \\
\hline $\begin{array}{l}\text { Cortex (posterior) } \\
\text { Hypothalamus } \\
\text { Medulla }\end{array}$ & $\begin{array}{l}36 \cdot 0 \\
26 \cdot 8 \\
21 \cdot 6\end{array}$ & $\begin{array}{l}10 \cdot 4 \\
23 \cdot 0 \\
14 \cdot 4\end{array}$ & $\begin{array}{c}18 \cdot 5^{*} \\
2 \cdot 8 \\
2 \cdot 1\end{array}$ & $\begin{array}{c}13 \cdot 2^{*} \\
2 \cdot 4 \\
1 \cdot 8\end{array}$ \\
\hline Animals & $\begin{array}{c}2 \\
\text { controls }\end{array}$ & $\begin{array}{l}2 \\
\text { controls } \\
\text { perfused }\end{array}$ & $\begin{array}{c}1 \\
\text { severe } \\
\text { lesion }\end{array}$ & $\begin{array}{c}1 \\
\text { severe } \\
\text { lesion } \\
\text { perfused }\end{array}$ \\
\hline
\end{tabular}

* Activities as multiple of control values.

Histological Appearances.-Three hours after freezing the damaged area was recognizable as a sector of cortex almost unstained in Nissl preparations. Neuronal and glial nuclei were just visible in the centre of the area while at the boundary between normal and frozen cortex there was a band of shrunken hyperchromatic neurones of which the apical and basal processes were stained for some distance beyond the cell body. Scattered throughout the lesion were numerous irregular spaces filled with a fine foam-like network and often continuous with greatly dilated perivascular spaces. The interpretation of these spaces was doubtful as either a colliquative necrosis of tissue or an escape of plasma from damaged vessels could be the causative factor.

The myelinated fibres immediately below the lesion were beaded and fragmented and presented a patchy, tigroid appearance under low power views. Small perivascular haemorrhages were sometimes seen the boundary zone.

At one week the border of the lesion was sharp\& demarcated and phagocytic disintegration of the dead tissue had begun, as evidenced by the presence of fat-laden scavenger cells in the floor of the lesiofep. Within the boundary zone the microglia wef activated but there was little change as yet in the astroglia.

During the next two to three weeks the salie histological changes were the complete invasion of the lesion by closely packed scavenger cells and the beginning of active mesodermal proliferation. The latter was seen as a fine collagenous networ particularly dense in the superficial part of the lesiof adjacent to the meninges and spreading inwards as ă more loosely arranged network. There was now di moderate increase in astrocytes (largely fibrous) in the boundary zone and a few patches of newo capillary formation could also be recognized in the same region. The zone of hyperchromatic cells was somewhat reduced and lay parallel and close to the edge of the lesion.

From one month onwards there was surprising little change in the microscopic appearance of the whole glio-mesodermal scar whose content of fag laden compound granular corpuscles seerned virtually unaltered even after seven months. Q the boundary presented evidence of a progressive process in the shape of an increasingly dense steen of connective tissue separating the lesion firm adjacent cortex and subcortical white matter.

In a few instances, patches of bone formation occurred in the depths of the scar and in general certain number of hyperchromatic cells persiste in the cortex just outside the connective tissue laye In this zone new capillary formation was at no timg considerable.

In view of the wide distribution of the modifica $\overrightarrow{\overrightarrow{0}}$ tions in vascular permeability, careful search waฐ made at all intervals after freezing for histologica evidence of oedema in the cortex (outside the lesion). the diencephalon, and the brain-stem. In none of these regions at any time was it possible to identif the appearances described as characteristic of oedema by Greenfield (1952) and Jacob (1940). Thus. demyelination of a patchy and partial nature occur\& only in the white matter immediately subjacent to the lesion. Swelling of astrocytes was to be seep only in the boundary zone and at no time was marginal gliosis to be traced further than 1.5 to. $2.0 \mathrm{~mm}$. beyond the edge of the lesion. The peri vascular spaces were not distended and the capillary endothelium appeared normal. Within the cortef there was no loss of cells and no changes werE్ 
evident in the intracortical axis cylinders or myelin sheaths.

\section{Discussion}

These experiments have revealed widespread increases in the content of radioactive D.I.F. and phosphate in the brain for many weeks after a cortical injury. In the region of the lesion there is a considerably increased amount of D.I.F. up to at least six weeks and of phosphate up to 14 weeks after freezing. These changes must be ascribed, at first, to the direct effect of low temperature on blood vessel walls and later to the abnormal permeability properties of the proliferating capillaries around the cortical scar. It is only in this region and during the first few hours that any histological evidence of oedema could be identified, all other parts of the brain appearing normal.

The raised activities in the contralateral cortex and in more remote parts, such as the medulla and hypothalamus, are most likely to be evidence of vasodilatation and its associated increased blood flow in vivo. A similar conclusion has been reached by Derrymaeker (1955) who carried out spectrophotometric assays of haemoglobin and trypan blue both in circulating blood and in nervous tissue from animals with experimental encephalitis, oedema, or cerebral allergy. Comparison with controls showed that while trypan blue in the tissue was increased, that of the contained haemoglobin was also increased but to a lesser extent. It was concluded that ". . . . this method shows the importance of vascular dilatation in the increased permeability of trypan blue".

Caution should be exercised, however, in ascribing to an increase in vascular permeability any increase in the amount of an indicator in a sample even when allowance has been made for residual blood in the dilated vascular bed. It is quite possible that the permeability of a unit area of capillary endothelium may not have changed but that the total area of endothelium and the capillary blood flow have increased as a result of vasodilatation. It is therefore only permissible to regard the remote and persistent effects as more or less increased penetration of D.I.F. or phosphate from a dilated capillary bed into a standard mass of tissue.

The genesis of this vasodilatation is obscure and it is only possible to draw attention to a few factors that may have causal significance.

From within a few minutes of the restoration of normal temperature the centre of the lesion will be bathed in the fluid derived from the damaged vessels in the boundary zone. Various diffusible constituents of the necrotic tissue may be expected to enter this fluid, including adenylic compounds some of which, e.g., adenylic acid and adenosine triphosphate, have a known vasodilator action. The extent of diffusion of such substances within the brain cannot be assessed but the role of the cerebrospinal fluid as a disseminator is suggested by the presence of adenylic compounds in it after concussion (Spiegel, SpiegelAdolf, and Wycis, 1946).

Greig and Holland (1949) and Greig and Mayberry (1951) have presented evidence to show that the acetylcholine/acetylcholinesterase system is normally involved in the maintenance of capillary permeability. A possible connexion between a disturbance of this system and the permeability changes associated with brain injuries is suggested by the identification of free acetylcholine in the cerebrospinal fluid after closed head injuries by Bornstein (1946) and by Tower and McEachern (1949), who also demonstrated a depressed level of acetylocholinesterase.

The possible importance of neural connexions in the mechanism of the remote vascular changes has been demonstrated by Tsang (vide supra). The prolonged staining of the ipsilateral lateral geniculate body following ablation of the visual cortex was regarded as the vascular concomitant of retrograde cell change with its associated gliosis. In the present experiments, however, the lesion was too small to produce recognizable changes of this type in any subcortical region. The absence of such changes may not necessarily exclude the participation of neural pathways, particularly if the developing scar could be regarded as a source of abnormal impulses passing to lower levels and producing vasodilatation and increased blood flow, such as were demonstrated by Santha and Cipriani (1938) in subcortical structures as a result of cortical stimulation.

While no direct assessment of local changes in human cerebral vascular permeability is possible, indirect evidence may be found in the response to drugs of cases of head injury. The experimental studies of Aird, Strait, Zealear, and Hrenoff (1952) have shown that the concentration of cocaine hydrochloride in the cerebral cortex of concussed cats was greater than in controls. Barbour and Abel (1910) reported a lowered threshold to the convulsive substance acid fuchsin in concussed animals and Dandy and Elman (1925) noted a similar result for absinthe after cortical or subcortical lesions. In human cases the sedative and analgesic drugs might provide the most useful information as they are more likely to be employed in the management and aftercare of cases of head injury. Of particular value would be evidence of any exaggeration of response, reduced latency of action, or the appearance of atypical pharmacological effects. 


\section{Summary}

A method employing liquid oxygen is described for the production of circumscribed lesions in the rabbit cerebral cortex.

Radioactive phosphate ${ }^{\left({ }^{32} \mathrm{P}\right)}$ and ${ }^{131} \mathrm{I}$-labelled fluorescein (D.I.F.), injected intravenously, were used as indicators of vascular changes in nervous tissue.

One litter, divided into control and experimental groups, was used for each period of survival, which for ${ }^{32} \mathrm{P}$ was 15 minutes to 14 weeks and for D.I.F. 30 minutes to six weeks.

Within the lesion there was increased penetration of the indicators, diminishing in degree throughout the survival ranges. Smaller long-lasting changes occurred in the adjacent and sometimes the contralateral cortex and also in the hypothalamus.

Increased penetration into the medulla, hippocampus, and cerebellum was less constant and persistent.

The cerebrospinal fluid was shown not to contribute to the increased concentrations in brain substance.

The increased ratios outside the lesion were interpreted as the result of vasodilatation in vivo.

The evolution of the histological appearances of the lesion is described.

The significance of the experimental results is discussed.
The author records with pleasure his indebtedness t $\overline{\bar{\alpha}}$ Professor A. Meyer for his interest and advice, t\& Dr. P. Merton for his critical perusal of the manuscrip and to Miss N. Billery and Mrs. B. Holder for they skilful assistance in the experimental, radioactive, and histological techniques.

\section{REFERENCES}

Aird, R. B., Strait, L. S., Zealear, D., and Hrenoff, M. (1952

Bakay, L. (1955). A.M.A. Arch. Neurol. Psychiat. 73, 2.

Barbour, H. G., and Abel, J. J. (1910). J. Pharmacol., 2, 167

Bornstein, M. B. (1946). J. Neurophysiol., 9, 349.

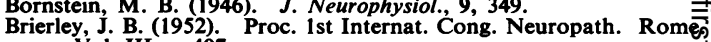
Vol. III, p. 407.

(1953a). Proc. Isotopes Technique Conference, 1951. Oxford I. p. 224. H.M.S.O.

(1953b). Unpublished results.

Broman, T., Radner, S., and Svanberg, L. (1949). Acta psychiat. (Kbh高. 24, 167.

Caudill, C. M., Smith, G. A., French, L. A., Peyton, W. T., an Moore, G. E. (1951). J. Neurosurg., 8, 423.

Dandy, W. E., and Elman, R. (1925). Bull. Johns Hopk. Hosp $36,40$.

Derrymaeker, A. (1955). Excerpta med. (Amst.), 8, 845. Derrymaeker, A. (1955). Excerpta med. (Amst.), 8, 845.
Greenfield, J. G. (1952). Proc. 1st Int. Cong. Neuropath., Rome,
Vol. I, p. 107.

Greig, M: E., and Holland, W. C. (1949). Science, 110, 237.

- and Mayberry, T. C. (1951). J. Pharmacol., 102, 1.

Jacob, H. (1940). Z. ges. Neurol. Psychiat., 168, 382. (Chicago), 3, 353.

Prados, M., Strowger, B., and Feindel, W. H. (1945). Ibid., 54, 16 .

Reiss, M., Badrick, F. E., and Halkerston, J. H. (1949). Biochem.

Santha, K. von, and Cipriani, A. (1938). Proc. Ass. Res. nerv. menił

Dis., 18, 346. 3 .

Stern, W. Eath. (Chicago), 42, 175. (1951). Proc. Soc. exp. Biol. (

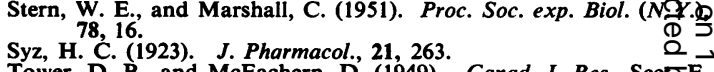

Tower, D. B., and McEachern, D. (1949). Canad. J. Res., Secod

Tsang, Y. C. (1936). Arch. Neurol. Psychiat (Chicago), 36, 569 